(C) 2018 IEEE. Personal use of this material is permitted. Permission from IEEE must be obtained for all other uses, in any current or future media, including reprinting/republishing this material for advertising or promotional purposes, creating new collective works, for resale or redistribution to servers or lists, or reuse of any copyrighted component of this work in other works. 


\title{
Waveform Approach for Assessing Conformity of CISPR 16-1-1 Measuring Receivers
}

\author{
Marco A. Azpúrua ${ }^{\circledR}$, Member, IEEE, Marc Pous, José A. Oliva, Borut Pinter, \\ Martin Hudlička, Senior Member, IEEE, and Ferran Silva, Fellow, IEEE
}

\begin{abstract}
An alternative approach for assessing the conformity of electromagnetic interference measuring receivers with respect to the baseline CISPR 16-1-1 requirements is proposed. The method's core is based on the generation of digitally synthesized complex waveforms comprising multisine excitation signals and modulated pulses. The superposition of multiple narrowband reference signals populating the standard frequency bands allows for a single-stage evaluation of the receiver's voltage accuracy and frequency selectivity. Moreover, characterizing the response of the weighting detectors using modulated pulses is more repeatable and less restrictive than the conventional approach. This methodology significantly reduces the amount of time required to complete the verification of the receiver's baseline magnitudes, because time-domain measurements enable a broadband assessment while the typical calibration methodology follows the time-consuming narrow band frequency sweep scheme. Since the reference signals are generated using arbitrary waveform generators, they can be easily reproduced from a standard numerical vector. For different test receivers, the results of such assessment are presented in the $9 \mathrm{kHz}-1 \mathrm{GHz}$ frequency range. Finally, a discussion on the measurement uncertainty of this methodology for assessing measuring receivers is given.
\end{abstract}

Index Terms-Calibration, electromagnetic interference, quality management, standards, time-domain measurements.

\section{INTRODUCTION}

$\mathbf{T}$ HE measuring receiver is the fundamental instrument for conducted and radiated electromagnetic emissions testing. According to the standard definition given by the CISPR 16-1-1:2015, it is an "instrument such as a tunable voltmeter, an electromagnetic interference receiver, a spectrum analyzer or a fast Fourier transform (FFT)-based measuring

Manuscript received July 1, 2017; revised December 13, 2017; accepted December 15, 2017. This work was supported in part by the EURAMET 15RPT01 Research Project (the EMPIR is jointly funded by the EMPIR participating countries within EURAMET and the European Union), in part by the Spanish Ministerio de Economía, Industria y Competitividad, under Project TEC2016-79214-C3-2-R (AEI/FEDER, UE), in part by the Secretaria d'Universitats i Recerca del Departament d'Economia i Coneixement de la Generalitat de Catalunya, and in part by the European Social Fund. The Associate Editor coordinating the review process was Dr. Mohamed AbouKhousa. (Corresponding author: Marco A. Azpúrua.)

M. A. Azpúrua, M. Pous, J. A. Oliva, and F. Silva are with the Group of Electromagnetic Compatibility, Department of Electronic Engineering, Universitat Politècnica de Catalunya, 08034 Barcelona, Spain (e-mail: marco.azpurua@upc.edu).

B. Pinter is with the Slovenian Institute of Quality and Metrology, 1000 Ljubljana, Slovenia (e-mail: borut.pinter@siq.si).

M. Hudlička is with the Czech Metrology Institute, $63800 \mathrm{Brno}$, Czech Republic (e-mail: mhudlicka@cmi.cz).

Color versions of one or more of the figures in this paper are available online at http://ieeexplore.ieee.org.

Digital Object Identifier 10.1109/TIM.2018.2794941 instrument, with or without preselection, that meets the relevant parts of this standard" [1]. In this regard, the standard CISPR 16-1-1 does not provide a particular implementation of a measuring receiver but a number of requirements that manufacturers have to fulfill under a "black-box" approach.

Therefore, assessing of the quantities and ranges that allow certifying the conformity of measuring receivers is mandatory. Such assessment employs calibration and verification results for determining if the measuring receiver performance is within the tolerance margins. However, the variety of implementations of EMI test receivers and the particularity of their requirements have led to a common situation in which the instrument manufacturer can be the only capable entity of performing a complete calibration of their own measuring receivers.

On the one hand, this is because the established method for calibrating the response to pulses of the standard weighing detectors, e.g., the quasi-peak (QP) detector, uses a baseband (nanosecond) pulse generator for providing a set of rectangular pulses with a fixed impulse area and repetition frequency [2]. Such a signal generator is an expensive piece of hardware that can hardly be used for other calibration setups. On the other hand, the vast number of magnitudes, functions, and ranges subject to calibration in modern EMI measuring receivers urges for automated calibration processes programmed for every different manufacturer and model in order to deliver calibration results in a reasonable time frame. Thus, the remarkable amount of resources and effort needed for implementing a specific calibration bench suitable for EMI measuring receiver undermines its widespread adoption by the third-party calibration providers.

At European level, National Metrology Institutes (NMIs) are concerned by the actual metrological capability (beyond the calibration services provided by the first parties) to provide complete calibration and traceability for EMI measuring receivers. In such conditions, it is likely that even accredited test houses are performing electromagnetic emissions testing without an adequate traceability required by the ISO/IEC 17025 standard. Actually, experience indicates that EMI test receivers are often calibrated as spectrum analyzers, which is insufficient. In fact, the critical functions of an EMI measuring receiver that are involved in the determination of compliance must be calibrated, including not only the reading of the spectrum level but also its frequency selectivity and response to pulses of the weighting detectors. Moreover, this situation could happen unnoticed if the procedures involved 


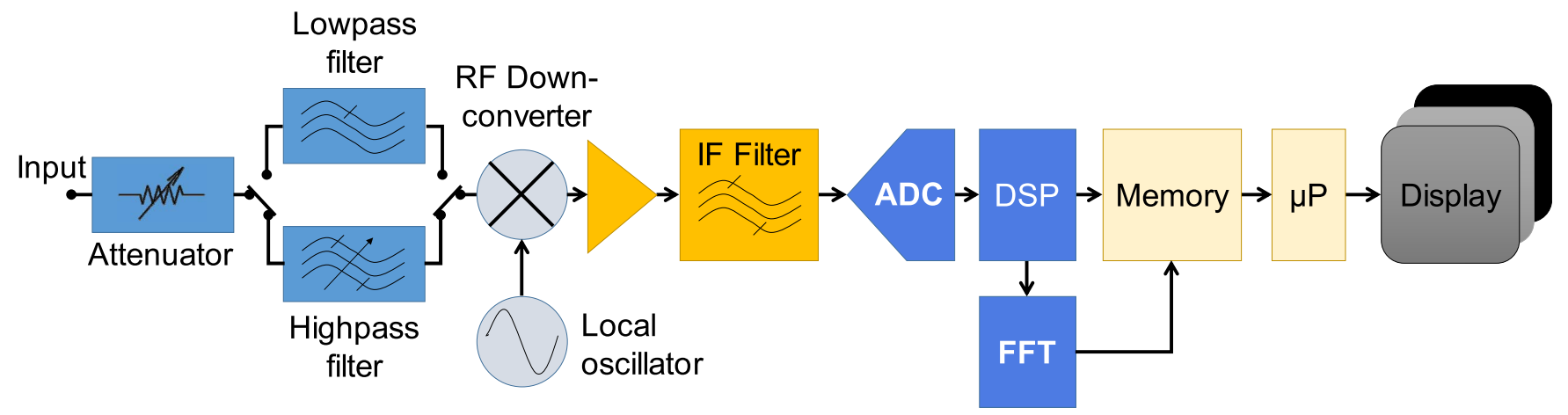

Fig. 1. Block diagram of a real-time EMI analyzer.

in testing and auditing the performance of EMI test receiver do not include specific CISPR 16-1-1 requirements. Hence, many EMI measuring receivers are being calibrated only according to the widespread guidelines used for spectrum analyzers [3], [4].

The abovementioned situation was acknowledged in a previous call from the European Metrology Programme for Innovation and Research (EMPIR), the ongoing Joint Research Project "Development of RF and Microwave Metrology Capability," also known as RFMicrowave (15RPT01), pointed out that "... current knowledge between EMC and RF\&MW laboratories is very weak, which reduces awareness in measurements/calibrations and, therefore the overall quality of both EMC and RF\&MW measurements" [5].

Particularly, the calibration of CISPR 16-1-1 pulse generators can be challenging in terms of the required accuracy in the determination of its spectral density, which is $\pm 0.5 \mathrm{~dB}$ [1], [6]. In a report from EURAMET, the results from an interlaboratory measurement comparison of a pulse generator in accordance with CISPR 16-1-1 were presented. From the six laboratories that participated, METAS, PTB, and Schwarzbeck successfully used a time-domain approach with ultrawideband oscilloscopes, while the other participants preferred to keep undisclosed their calibration method. However, the spread of the results cannot be explained by the uncertainties quoted by the participants [7].

In that sense, a strategy posed by the metrology community for bridging this gap is to introduce a whole new set of more repeatable, reproducible, and less hardware stringent calibration and verification methods suitable for EMI measuring receivers. Previously, the authors presented an automated method for verifying the compliance of full time-domain EMI (TDEMI) measurement systems. The verification method has five stages that cover the baseline parameters that allow an EMI measuring receiver to be compliant with CISPR 16-1-1 requirements, that is, sine-wave voltage accuracy, absolute and relative response to pulses, frequency selectivity, and voltage standing wave ratio (VSWR). Some satisfactory results were presented for the $9 \mathrm{kHz}-30 \mathrm{MHz}$ frequency range, which covers the CISPR bands A and B typically related to conducted EMI measurements. The setup employed for the verifications is very compact and uses an arbitrary waveform generator (AWG) and a vector network analyzer (VNA) as standard reference equipment [8].
The continuation of that work is presented here as a timedomain waveform approach for assessing conformity of EMI measuring receivers. By using synthesized multisine excitation signals and modulated pulses, the proposed methodology is aimed to characterize the accuracy, response to pulses, and selectivity of the test receiver using a more accessible and agile strategy, and is addressed to match specific requirements of the FFT-based measuring receivers, including the new generation of real-time EMI measuring systems and also oscilloscopebased implementations of the test receivers, since they can benefit the most from the time-domain measurements.

The structure of this paper is as follows. In Section II, an explanation of two remarkable types of FFT-based EMI measurement system is given. Then, Section III summarizes the key CISPR 16-1-1 requirements that EMI measuring receivers must comply with. Next, Section IV proceeds with the description of the proposed approach for conformity assessment in terms of the standard waveforms and their timeand frequency-domain behaviors. Finally, Section V presents some relevant measurement results of the baseline magnitudes of an oscilloscope-based TDEMI measurement system, and a comparison with the measurement results obtained with a swept receiver is used for cross validation. At the end of this paper, a discussion of scalability of this verification method for calibrating test receivers is presented along with the conclusions of this paper.

\section{Overview of FFT-BASED EMI MEASURING RECEIVERS ARCHITECTURES}

The modern generation of measuring receivers has embraced FFT-based capabilities not only for speeding up emissions' testing but also to provide time-domain and timefrequency analysis features useful for evaluating and mitigating the impact of transient and stochastic disturbances [9]. Currently, real-time analyzers and oscilloscope-based implementations are two differentiated approaches for implementing FFT-based measuring receivers. In this section, both of them are briefly explained in the light of CISPR 16-1-1 compliance feasibility.

\section{A. Real-Time Analyzers}

A block diagram of the real-time EMI analyzer's architecture is shown in Fig. 1. This type of measuring receiver 


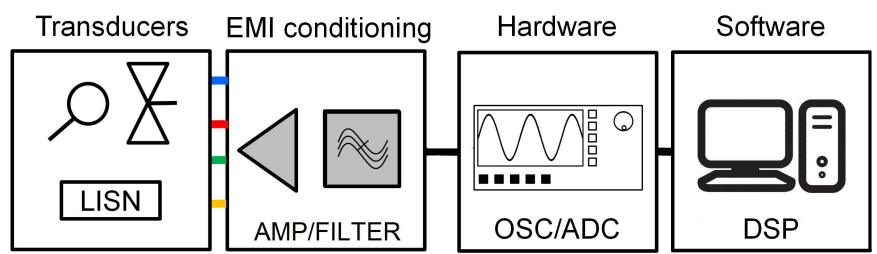

Fig. 2. Block diagram of a full TDEMI measurement system.

uses the mixer and the local oscillator to convert the input signal to a constant intermediate frequency (IF), similarly as with the heterodyne architecture. At IF, the signal is sampled fulfilling the Nyquist criterion using analog-to-digital converters (ADCs) and filtered to avoid aliasing. The timeand value-discrete IF signals are digitally downconverted to baseband and then processed for obtaining the signal spectrum. There are two possibilities for preparing a frequency-domain display. The first one is using digital filters of certain resolution bandwidth (RBW) for emulating the functioning of an analog spectrum analyzer. The second option is to calculate the spectrum of that portion of the spectrum using the FFT with the corresponding windowing for achieving the exact RBW setting. In both cases, it is still necessary to run through the frequency range that has been set on, which means that for spans larger than the IF bandwidth, several iterations of the acquisition are required [10], [11].

\section{B. Full Time-Domain EMI Measurement Systems}

Full TDEMI measurement systems are oscilloscope-based implementations of an EMI measuring receiver. In general terms, a full TDEMI measurement system is described by the block diagram shown in Fig. 2 [12], [13]. For the measurement of radiated EMI, a broadband antenna shall be used, while for the measurement of conducted EMI corresponds either a current clamp or a line impedance stabilization network. The measured signal could be amplified or filtered if this provides better sensitivity. In the ADC, the full spectrum signal is digitized in real time and stored in as a time-discrete valuediscrete signal.

The final measurement results are computed via the processing techniques implemented in a software layer that provides compliance with the relevant CISPR 16-1-1 requirements.

A screenshot of an actual implementation of the full TDEMI by the Electromagnetic Compatibility Group (GCEM) of the Universitat Politècnica de Catalunya (UPC) is shown in Fig. 3. After deep memory acquisitions, the software of the full TDEMI measurement system performs signal processing tasks, including windowing, resolution enhancing, resampling, spectral estimation (using the short-time FFT and Welch's method), and the detector emulation. Those mathematical transformations are responsible for delivering the measurement results in accordance with CISPR 16-1-1 requirements [13].

Full TDEMI measurement systems capture the whole spectrum of the EMI with every acquisition enabling multidomain analysis. Besides, the triggering and multichannel capabilities found in most oscilloscopes provide additional tools for testing multifunctional mode equipment and for emissions testing parallelization. On the other hand, much higher sampling rates and a deeper memory are required than with real-time analyzers. This imposes bandwidth and dwell-time constraints based on the current oscilloscope technology.

\section{Conformity Assessment Needs}

Even though real-time analyzers are the intrinsically suitable approach for reaching the higher frequencies with sufficient dynamic range and sensitivity, both architectures are converging in some aspects. For instance, commercial real-time analyzers are offering a larger IF bandwidth. That is the case of the TDEMI $X$ from GAUSS Instruments, the FSW-B512R from Rohde \& Schwarz, or the N9030B-RT1 from Keysight Technologies having 645, 512, and $510 \mathrm{MHz}$ of IF bandwidth, respectively. Conversely, oscilloscopes with an effective number of bits [14] suitable for general EMI measurements below $1 \mathrm{GHz}$ are common nowadays. Moreover, PC-based oscilloscopes are more popular as the processing power and the speed of the communication interfaces allow for faster data transfer and software-based processing.

As both the described architectures for FFT-based measuring receivers play an important role in EMI compliance testing, they need a specific approach for assessing their conformity with regard the relevant CISPR 16-1-1 requirements [15], [16]. Research on such aspects has been partially undergone previously, mainly in charge of the first party developers and manufacturers [17]-[19]. Furthermore, a standardized method for performing calibrations and verification of the FFT-based measuring receivers in terms of the CISPR 16-1-1 requirements is not currently available. Sections IV and V will deepen in such matters after the following enumeration of the baseline requirements for EMI measuring receivers.

\section{STANDARD BASELINE REQUIREMENTS FOR ELECTROMAGNETIC INTERFERENCE MEASURING RECEIVERS}

The normative Annex K "Calibration requirements for measuring receivers" of the CISPR 16-1-1 provides two alternatives with regard to the demonstration of compliance of measuring receivers. The first possibility is using the manufacturer's calibration method for assessing compliance. As stated before, in many cases, this is neither feasible for manufacturerindependent nor for in-house calibration laboratories, because manufacturer's calibration method can hardly be reproduced due to the lack of procedural information and/or hardware resources, e.g., the CISPR pulse generator. The alternative is using a calibration or a traceable verification process that includes at least the following parameters: VSWR, sine-wave voltage accuracy, response to pulses, and selectivity.

Tables I and II summarize the standard baseline requirements applicable to EMI measurement systems in CISPR bands A-D. Those items constitute the baseline (minimum) set of requirements that shall be covered by any calibration or verification method.

Please note that a typical calibration certificate of an EMI measuring receiver may include other additional performance 


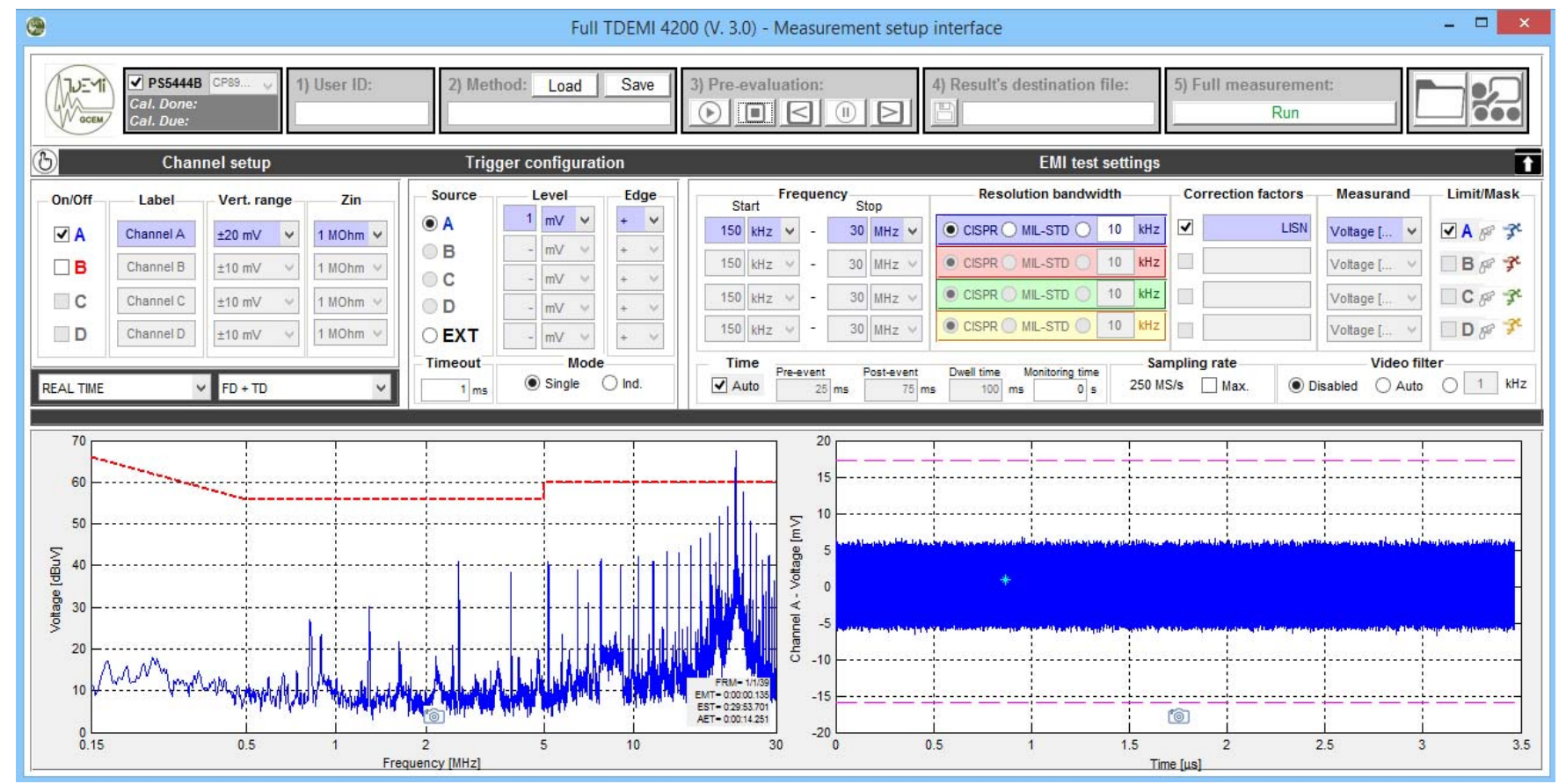

Fig. 3. Graphical user interface of the full TDEMI measurement setup panel.

TABLE I

BASELINE CISPR 16-1-1 REQUIREMENTS FOR ELECTROMAGNETIC INTERFERENCE MEASURING RECEIVERS

\begin{tabular}{|c|c|c|c|}
\hline Parameter & Subclause & $\begin{array}{l}\text { Baseline standard } \\
\text { requirements }\end{array}$ & Freq. ranges \\
\hline VSWR & $\begin{array}{l}4.2,5.2 \\
6.2,7.2\end{array}$ & $\begin{array}{c}2.0 \text { to } 1 \\
\text { ( } 0 \mathrm{~dB} \text { RF attenuation) }\end{array}$ & $9 \mathrm{kHz}-1 \mathrm{GHz}$ \\
\hline $\begin{array}{l}\text { Sine wave } \\
\text { voltage } \\
\text { accuracy }\end{array}$ & $\begin{array}{l}4.3,5.4 \\
6.4,7.4\end{array}$ & $\begin{array}{c}\text { Better than } \pm 2 \mathrm{~dB} \\
(50 \Omega \text { resistive source } \\
\text { impedance) }\end{array}$ & $9 \mathrm{kHz}-1 \mathrm{GHz}$ \\
\hline $\begin{array}{l}\text { Response to } \\
\text { pulses }^{\text {a }} \\
\text { (Absolute) }\end{array}$ & $\begin{array}{l}4.4,5.5 \\
6.5,7.5\end{array}$ & $\begin{array}{l}66 \mathrm{~dB}(\mu \mathrm{V}) \pm 1.5 \mathrm{~dB} \\
\text { (Flat spectrum within the } \\
\text { measured bandwidth) }\end{array}$ & $\begin{array}{l}\text { CISPR Bands A, } \\
\text { B, C and D }\end{array}$ \\
\hline $\begin{array}{l}\text { Response to } \\
\text { pulses }^{\mathrm{a}} \\
\text { (Relative) }\end{array}$ & $\begin{array}{l}4.4,5.5 \\
6.5,7.5\end{array}$ & Table II. & $\begin{array}{l}\text { CISPR Band A, } \\
\text { B, C and D }\end{array}$ \\
\hline \multirow{3}{*}{ Selectivity ${ }^{\mathrm{b}}$} & \multirow{3}{*}{$\begin{array}{l}4.5,5.6 \\
6.6,7.6\end{array}$} & $\begin{aligned} 90 \mathrm{~Hz} & \leq B_{1,5} \leq 220 \mathrm{~Hz} \\
180 \mathrm{~Hz} & \leq B_{6} \leq 220 \mathrm{~Hz} \\
180 \mathrm{~Hz} & \leq B_{20} \leq 440 \mathrm{~Hz} \\
4 \mathrm{kHz} & <B_{1,}<10 \mathrm{kHz}\end{aligned}$ & CISPR Band A \\
\hline & & $\begin{array}{c}4 \mathrm{KHz} \leq B_{1,5} \leq 10 \mathrm{KHz} \\
8 \mathrm{kHz} \leq B_{6} \leq 10 \mathrm{kHz} \\
10 \mathrm{~Hz} \leq B_{20} \leq 20 \mathrm{kHz}\end{array}$ & CISPR Band B \\
\hline & & $\begin{array}{l}40 \mathrm{kHz} \leq B_{1,5} \leq 140 \mathrm{kHz} \\
100 \mathrm{kHz} \leq B_{6} \leq 140 \mathrm{kHz} \\
100 \mathrm{kHz} \leq B_{20} \leq 280 \mathrm{kHz}\end{array}$ & $\begin{array}{l}\text { CISPR Bands } \\
\text { C and D }\end{array}$ \\
\hline
\end{tabular}

tests. However, since partial calibration is allowed by CISPR 16-1-1, the forthcoming description focuses on those that are mandatory, critical, and/or different from the typical tests calibrated in spectrum analyzers. Moreover, given that the superheterodyne type of receivers has been excluded from the scope of this paper, all the specifications that are not relevant for the generality of FFT-based EMI measurement systems have been omitted.
With regard to the requirements highlighted above, some clarifications shall be made: 1) VSWR requirements are only applicable to the $0-\mathrm{dB}$ RF attenuation condition, conversely if $\mathrm{RF}$ attenuation is used, the VSWR must be lower than $1.2 ; 2$ ) narrowband verifications at discrete suggested frequencies (the start, stop, and center frequencies) are replaced by broadband measurements; 3 ) the pulse repetition frequencies considered are above $10 \mathrm{~Hz}$, because this is the lowest mandatory pulse repetition frequency that is common to all CISPR frequency bands; and 4) for multichannel EMI measurement system, each channel shall be individually and independently verified.

\section{WAVEFORM APPROACH FOR ASSESSING CONFORMITY OF CISPR 16-1-1 MEASURING RECEIVERS}

As mentioned in Section I, the proposed methodology is based on the exploitation of the AWG for the generation of reference excitation signals employed for assessing the compliance with CISPR16-1-1 baseline requirements. The VSWR verification is excluded from the scope of the method, since VNA-based measurements are easier and more suitable for this purpose. The explanation of this approach is subdivided into sine-wave and pulse response measures, as follows.

\section{A. Sine-Wave Measures}

Conventionally, the method for calibrating the sine-wave accuracy in EMI measuring receivers consists in applying a single tone with a well-known level and frequency and amplitude. The reading of all the standard detectors must be identical. The voltage of the excitation signal is indirectly measured with a reference power meter.

Instead, the proposed approach uses an AWG for synthesizing a multisine-wave signal as the excitation. In that sense, 
TABLE II

Requirements For the Relative Pulse Response of the STANDARD WEIGHTING DETECTORS

\begin{tabular}{|c|c|c|c|c|c|}
\hline Band & $\begin{array}{l}f_{\text {rep }} \\
(\mathrm{Hz})\end{array}$ & $\begin{array}{c}\mathrm{PK} / \mathrm{QP} \\
(\mathrm{dB})\end{array}$ & $\begin{array}{c}\mathrm{QP} / \mathrm{QP}_{\text {(ref) }} \\
(\mathrm{dB})\end{array}$ & $\begin{array}{c}\mathrm{AV} / \mathrm{QP} \\
(\mathrm{dB})\end{array}$ & $\begin{array}{c}\text { RMS/QP } \\
(\mathrm{dB})\end{array}$ \\
\hline \multirow{4}{*}{ 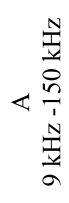 } & 10 & $10.1 \pm 1.5$ & $4.0 \pm 1.0$ & & $8.2 \pm 1.5$ \\
\hline & 25 (ref) & $6.1 \pm 1.5$ & 0 & $12.4 \pm 1.5$ & $4.2 \pm 1.5$ \\
\hline & 60 & $3.1 \pm 1.5$ & $-3.0 \pm 1.0$ & & \\
\hline & 100 & $2.1 \pm 1.5$ & $-4.0 \pm 1.0$ & & $-1.8 \pm 1.5$ \\
\hline \multirow{5}{*}{$\begin{array}{r}\sum^{N} \\
0 \\
0 \\
\infty \\
1 \\
1 \\
\frac{N}{v} \\
0 \\
0\end{array}$} & 10 & $16.6 \pm 1.5$ & $10.0 \pm 1.5$ & & $24.3 \pm 2.0$ \\
\hline & 20 & $13.1 \pm 1.5$ & $6.5 \pm 1.0$ & & \\
\hline & 100 (ref) & $6.6 \pm 1.5$ & 0 & $32.9 \pm 1.5$ & $14.3 \pm 1.5$ \\
\hline & 500 & & & $22.9 \pm 1.5$ & \\
\hline & 1000 & $2.1 \pm 1.5$ & $-4.5 \pm 1.0$ & $17.4 \pm 1.5$ & $4.3 \pm 1.5$ \\
\hline \multirow{5}{*}{ 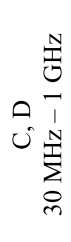 } & 10 & & $14.0 \pm 1.5$ & & \\
\hline & 20 & & $9.0 \pm 1.0$ & & \\
\hline & 100 (ref) & $12.0 \pm 1.5$ & 0 & & $20.1 \pm 1.5$ \\
\hline & 1000 & & $-8.0 \pm 1.0$ & $38.1 \pm 1.5$ & $10.1 \pm 1.0$ \\
\hline & 5000 & & & $26.3 \pm 1.5$ & \\
\hline
\end{tabular}

let us define a standard periodic signal $x(t)$ formed by a well-known combination of tones with controlled amplitude, frequencies, and phases as

$$
x(t)=\sum_{i=1}^{N_{\text {tones }}} A_{i}\left(f_{i}\right) \sin \left(\left(2 \pi f_{i}\right) t+\phi_{i}\left(f_{i}\right)\right)
$$

where $A_{i}, f_{i}$, and $\phi_{i}$ are, respectively, the amplitude, frequency, and phase of the $i$ th tone and $N_{\text {tones }}$ is the number of tones conforming $x(t)$.

Such signal is designed for providing independent control for the amplitude and phase of each tone, which allows adjusting the crest factor in the time domain [20]. Then, $x(t)$ is numerically sampled at a rate $f_{s} \geq 2 f_{\max }$, where $f_{\max }$ is the upper bound of the frequency range to be evaluated. A sampling rate greater than or equal to the sampling rate of the measuring receiver is recommended.

A time-discrete signal $x[n]$ is then obtained, where $n=0,1,2 \ldots$ is the integer variable used as the time step index. At that point, a time period of $x[n]$ is normalized and transformed into a discrete-valued signal with the same resolution of the AWG's digital-to-analog converter (DAC). Such time- and value-discrete vector is configured in the AWG and its DAC's output is smoothed by the interpolation filter and then scaled for approximating the voltage waveform as faithfully as possible, obtaining $\hat{x}[n]$. Fig. 4 shows, as an example, a period of a normalized multisine-wave excitation signal.

Considering the theoretical value of $\hat{x}[n]$ is exactly known, it can be used for calculating the reference spectrum, $\hat{X}[f]$, of the excitation signal. Welch's method for spectral estimation is used as explained in [12] and [21]. An appropriate windowing function for providing a suitable RBW must be selected, e.g., the Gaussian or the Kaiser-Bessel functions [13]. Window overlapping of more than $90 \%$ is recommended for reducing scalloping errors.

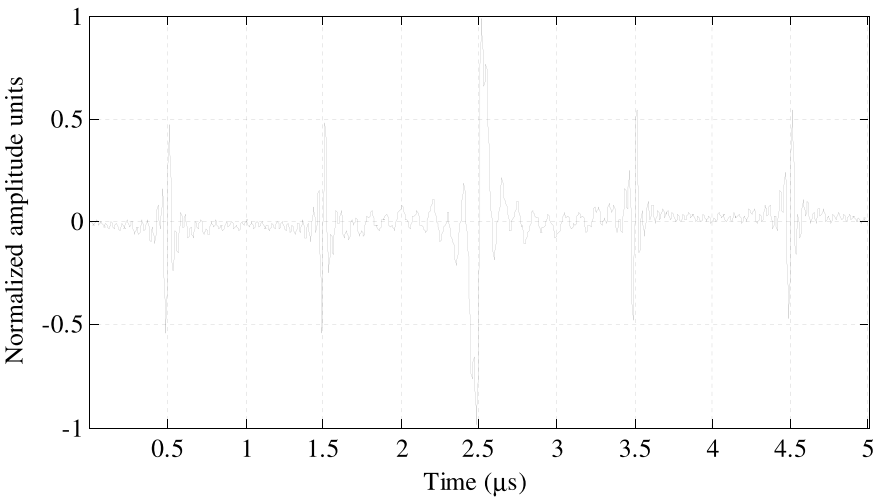

Fig. 4. Example of a multisine-wave excitation signal for assessing CISPR band $\mathrm{B}$.

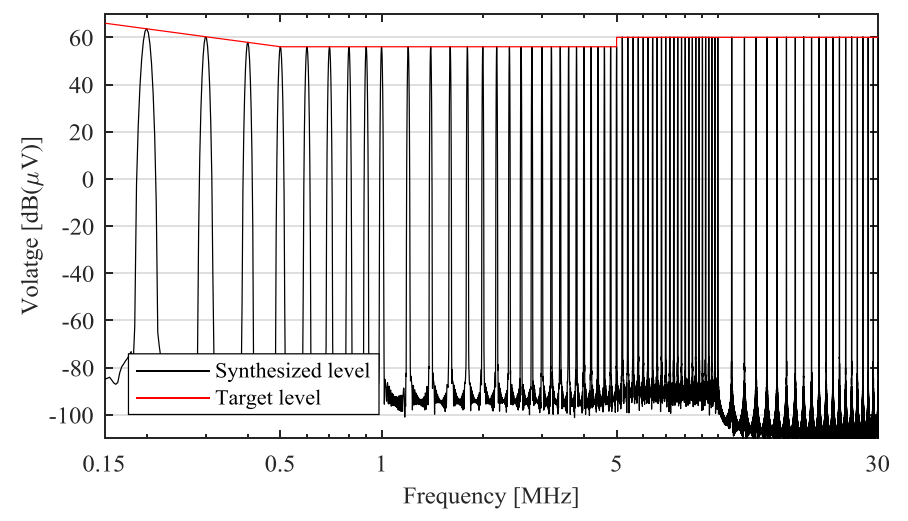

Fig. 5. Reference spectrum of a multisine-wave excitation signal that follows the CISPR 32 class B QP emissions' limit.

Fig. 5 shows the amplitude spectrum calculated from the theoretical excitation signal used in the previous example. Please note that the time-domain waveform was designed for providing tones with frequency-dependent amplitudes that follow the CISPR 32 limit line defined for class B equipment when using the QP detector. Beware, CISPR 16-1-1 does not specify the particular signal level at which the sine-wave level error calibration must be performed. However, authors recommend using the emissions' limit lines as the target for adjusting the excitation signal level, since this is the condition in which measurement accuracy is critical for determining compliance with EMC standards.

Nonetheless, other criteria can be used for designing the waveform of the excitation signal. For instance, pseudorandom and independent amplitudes, frequency, and phases can provide a noise-like multisine wave that allows obtaining statistical information about the variability of the assessed quantities.

In any case, the multisine-wave excitation signal must be fed to the measuring receiver for measuring its spectrum. The sine-wave accuracy is assessed by calculating the error in the voltage measured with respect to the reference value (previously calculated) at the exact frequencies for which the tones were generated.

On the other hand, selectivity requirements are assessed by iteratively measuring the 1.5-, 6-, and 20-dB decay bandwidths for each tone generated. Finally, please note that the frequency 
TABLE III

STANDARD IMPULSE AREA SPECIFICATION

\begin{tabular}{cc}
\hline \hline Frequency Band & Impulse area $(\boldsymbol{\mu V \mathbf { V s } )}$ \\
\hline \hline A & 13.5 \\
B & 0.316 \\
C & 0.044 \\
D & 0.044 \\
\hline
\end{tabular}

spacing of the multisine waveforms should respect RBW requirements for avoiding the component's overlapping.

\section{B. Absolute and Relative Pulse Response}

According to CISPR-16-1-1, the absolute and relative pulse response for the peak, $\mathrm{QP}$, average (AV), and rms detectors shall be evaluated. The aim of these pulse measures is to emulate the broadband-impulsive interferences, which are common in EMC tests. The requirements of these pulses are described in CISPR 16-1-1, defining they must be flat in the frequency band under assessment with a level equivalent to a tone having an rms voltage of $2 \mathrm{mV}$, which means $66 \mathrm{~dB}(\mu \mathrm{V})$. These flat pulses are applied for different repetition rates in order to obtain a certain ratio between peak, QP, AV, and rms detectors, weighting the repetitiveness of the measured interferences [1].

In the CISPR 16-1-1, the waveform of the pulses is defined in open-circuit conditions according to their impulse area, and those specifications are reproduced in Table III.

Therefore, if we consider the pulses are perfectly rectangular, the amplitude of the required impulse is given by

$$
A_{\text {imp }}=U_{\text {peak }} \times T_{d}
$$

where $U_{\text {peak }}$ is the peak voltage of the RF-modulated signal during ON state and $T_{d}$ is the duration time of RF impulse in the course of the ON condition.

With the standard approach, it is technically possible to generate such flat pulse at all the frequency range for CISPR bands A-D. However, this is no longer feasible for higher frequencies, because there are no pulse generators capable of producing such extremely high voltage in fractions of picoseconds. That is why CISPR 16-1-1 indicates that "above $1 \mathrm{GHz}$, the required impulse area is defined using a pulse-modulated carrier at the frequency of test..." Therefore, in CISPR 16-1-1 Annex E, an alternative method is mentioned for the impulse evaluation above $1 \mathrm{GHz}$.

Nonetheless, in the proposed approach the AWG was only used for synthetizing the standard pulses for bands A and B while and for bands $\mathrm{C}$ and $\mathrm{D}$ the pulse-modulated RF technique mentioned in CISPR 16-1-1 Annex E was adapted. Therefore, we propose employing this technique for frequencies below $1 \mathrm{GHz}$ as this procedure is easy to implement and it is already widely accepted for larger frequencies, as demonstrated by the accreditation of such procedure held by recognized NMIs.

Hence, the test setup for assessing the absolute and relative pulse response of the measuring receivers is according to Fig. 6.

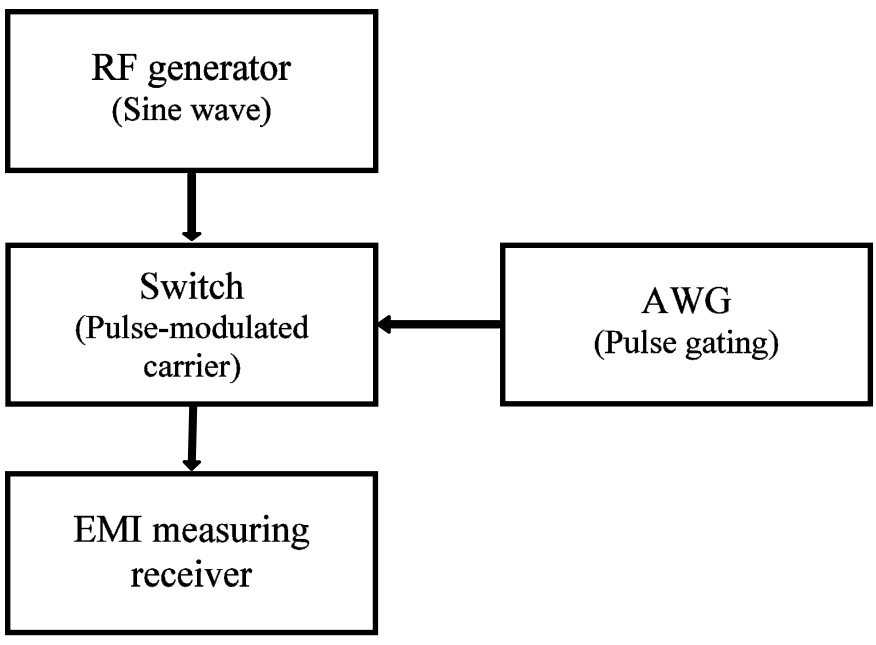

Fig. 6. Simplified block diagram of the test setup for assessing the absolute and relative pulse response of the measuring receivers.

TABLE IV

Reference Pulse Duration and Amplitude SPECification

\begin{tabular}{ccc}
\hline \hline Frequency Band & $\boldsymbol{T}_{\boldsymbol{d}}(\boldsymbol{\mu s})$ & $\mathbf{U}_{\mathbf{r m s}}(\mathbf{m V})$ \\
\hline \hline $\mathrm{A}$ & 100 & 95.5 \\
$\mathrm{~B}$ & 2.2 & 101.6 \\
$\mathrm{C}$ & 0.167 & 186.3 \\
$\mathrm{D}$ & 0.167 & 186.3 \\
\hline
\end{tabular}

The RF generator provides a continuous wave signal at the different frequencies selected for bands $\mathrm{C}$ and $\mathrm{D}$. Then, the AWG produces the gating signal that modulates the carrier by switching $\mathrm{ON}$ and $\mathrm{OFF}$ the $\mathrm{CW}$ signal, creating a pulse according to CISPR16-1-1 requirements. Finally, the modulated pulse is fed directly to the EMI measuring receiver. The amplitude of the CW signal and the gating duration are defined in Table IV for bands A-D.

The specific carrier frequency and pulse repetition frequency of the modulating pulse must be iteratively configured to provide the excitation waveform suitable to evaluate the pulse response of the EMI measuring receiver in the conditions specified in Table I. As an example, Fig. 7 shows a $1-\mathrm{GHz}$ pulse-modulated signal with a $1-\mathrm{kHz}$ repetition frequency generated for assessing the response to pulses of a measuring receiver in CISPR bands $\mathrm{C}$ and $\mathrm{D}$.

\section{RESUlts}

The following results are referred to the assessment of conformity performed on two different versions of full TDEMI measurement systems. The oscilloscopes involved are the PicoScope 5444B from Pico Technologies (OSC1) and the DPO5104B from Tektronix (OSC2).

The PicoScope 5444B has a 200-MHz bandwidth, a maximum sampling rate of $1 \mathrm{GSamples/s,} 512 \mathrm{MSamples}$ of memory depth, and its nominal input impedance is $1 \mathrm{M} \Omega$. Therefore, an external 50- $\Omega$ matching load was connected in parallel to each oscilloscope's input channel. This measurement system is typically used for conducted EMI measurement, and thus it was assessed in CISPR bands A and B. 

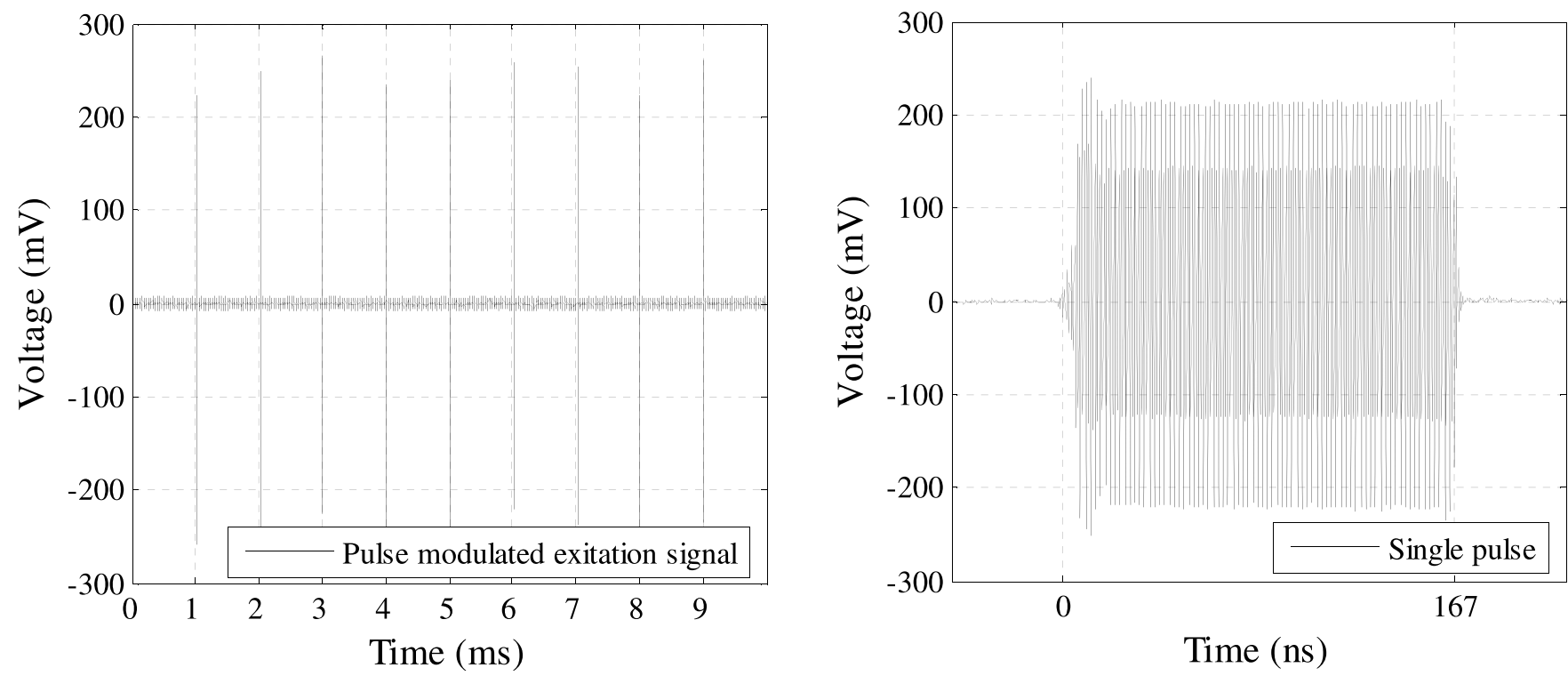

Fig. 7. Example of a 1-GHz pulse-modulated signal with a 1-kHz repetition frequency generated for assessing the response to pulses of a measuring receiver in CISPR bands $\mathrm{C}$ and $\mathrm{D}$.

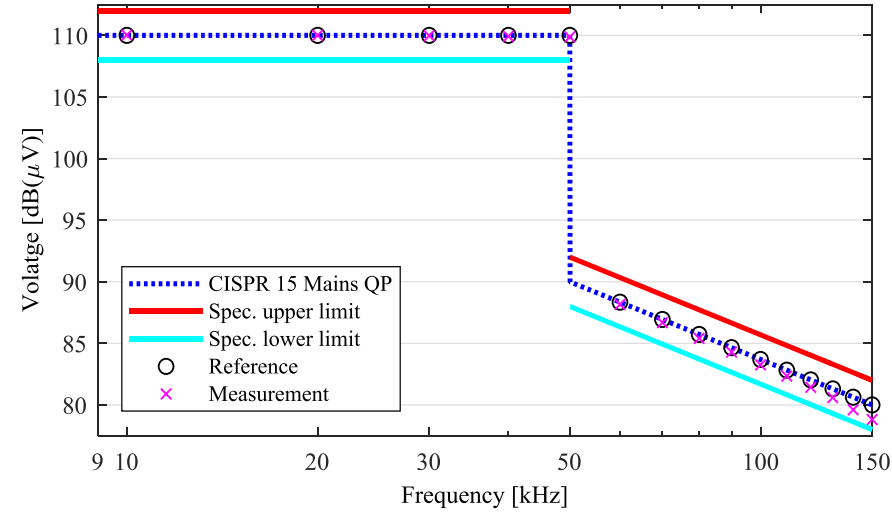

Fig. 8. Band A sine-wave accuracy assessment with respect to CISPR 15 QP emissions' limits for a full TDEMI measurement system.

The DPO5104B has a 1-GHz bandwidth, a maximum sampling rate of $10 \mathrm{GSamples} / \mathrm{s}, 50$ MSamples of memory depth, and its nominal input impedance can be set to $50 \Omega$. This measurement system is more suited for radiated EMI measurement, and thus it was assessed in CISPR bands C and D. In practice, it may require additional external preamplification for increasing the sensitivity of the measurement system [12].

For generating the multisine-wave excitation signals, a pulse function arbitrary generator model $81160 \mathrm{~A}$ from Keysight Technologies was used. It has a DAC with 14 bit of vertical resolution at $2.5 \mathrm{GSamples} / \mathrm{s}$ and a $330 \mathrm{-MHz}$ bandwidth for pulses extendable to $500 \mathrm{MHz}$ for single tones.

An additional signal generator from Rohde \& Schwarz model SML was employed for providing the sine wave in the assessment bands C and D. The switch Mini-circuits ZSWA-4-30DR was used in the pulse response test setup for modulating the sine waves according to the general procedure previously explained.

Cable attenuation was corrected in measurements. In all cases, low loss 50- $\Omega$ coaxial cables were used and their attenuation was measured for each frequency band.

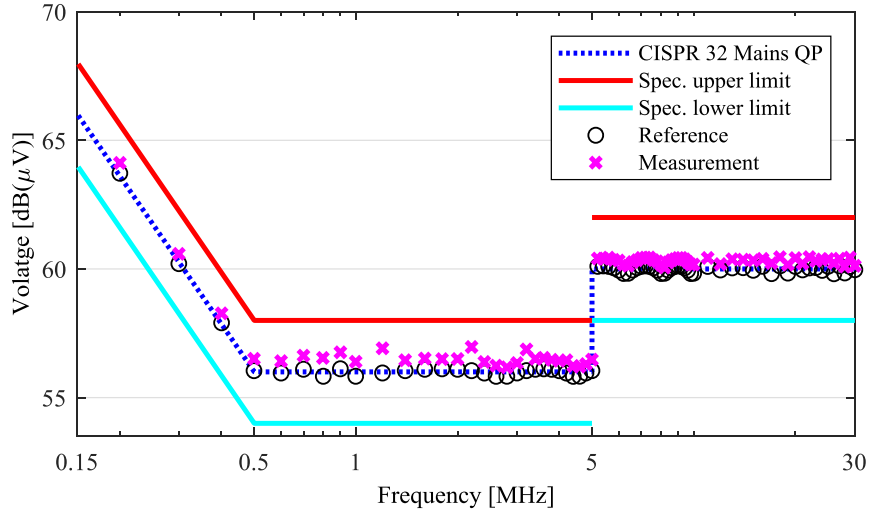

Fig. 9. Band B sine-wave accuracy assessment with respect to CISPR 32 QP class B emissions' limits for a full TDEMI measurement system.

\section{A. Multisine-Wave Measurements}

Previously, it was mentioned that different criteria could be used in the definition of the waveform of the test signal. In this regard, the multisine-wave signal employed for assessing OSC1 was designed using a couple of standard limit lines as reference. Conversely, OSC2 was evaluated using a pseudorandom selection of the amplitude of the individual tones. It is important to state that, even if neither criterion is preferred in terms of assessing compliance with CISPR 16-1-1 baseline requirements, however, they can deliver different insights, as it will be shown in what follows.

Figs. 8 and 9 show the measurement results of the sinewave accuracy assessment performed for the abovementioned measuring receiver in CISPR bands A and B, respectively. In both figures, the blue dashed line represents the target level and the red and cyan lines provide an indication of the tolerance defined in Table I. Likewise, the black circles correspond to the achieved reference level, while the magenta markers symbolize the measurement result. 


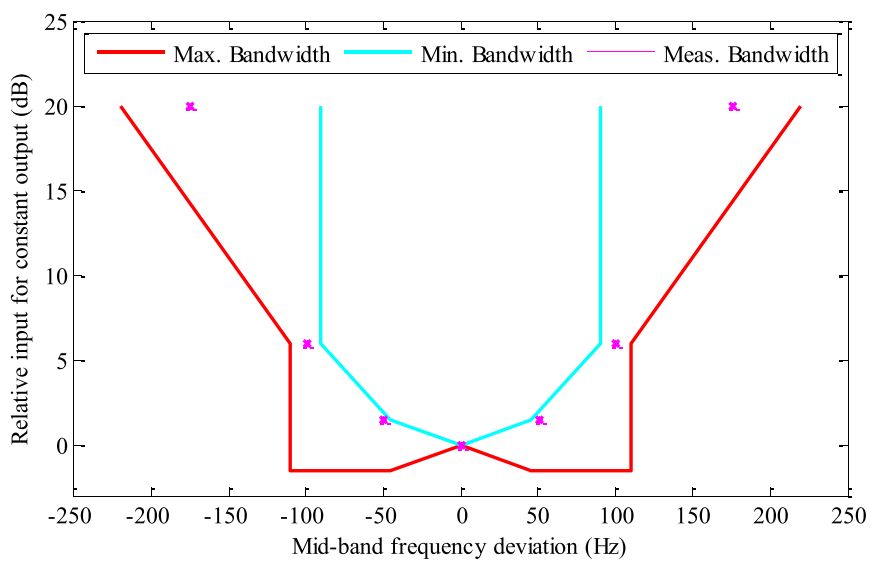

Fig. 10. Band A frequency selectivity assessment with respect to the equivalent IF filter mask.

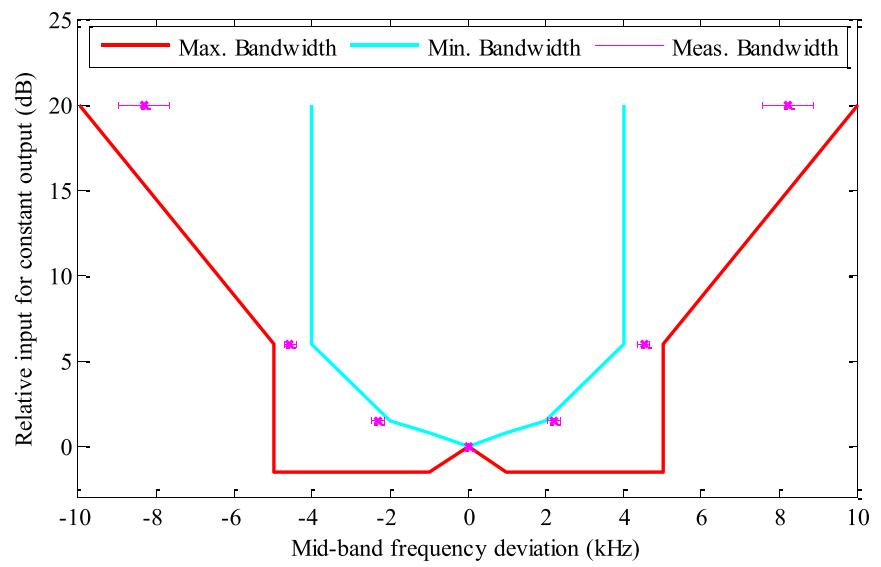

Fig. 11. Band B frequency selectivity assessment with respect to the equivalent IF filter mask.

On the one hand, band A target level was selected based on the QP limits for radio disturbances applicable to electrical lighting equipment according to the CISPR 15 standard [23]. On the other hand, band $\mathrm{B}$ target level was chosen based on the QP emissions limits for class $\mathrm{B}$ (domestic) equipment according to the CISPR 32 standard [24].

In both cases, just a single measurement was required for assessing the compliance of each CISPR band in terms of the accuracy of sine-wave measures, which, in this case, is favorable because worst case errors are lower than $\pm 1 \mathrm{~dB}$.

Moreover, the same measurement results were used for calculating the 1.5-, 6-, and 20-dB decay bandwidth at each frequency component of the spectrum. Figs. 10 and 11 present the midband frequency deviation obtained from previous measurements. Mean values are marked with an " $x$ " along with an error bar symbolizing the range of the variations of each measure. Again, results demonstrate compliance with CISPR 16-1-1 standard requirements.

Fig. 12 shows the summary of the measurement results from the sine-wave accuracy, frequency error, and selectivity assessment performed using pseudorandomly generated sine-wave excitations signals in bands C and D; 200 sine waves with random amplitude, frequency, and phase were generated at
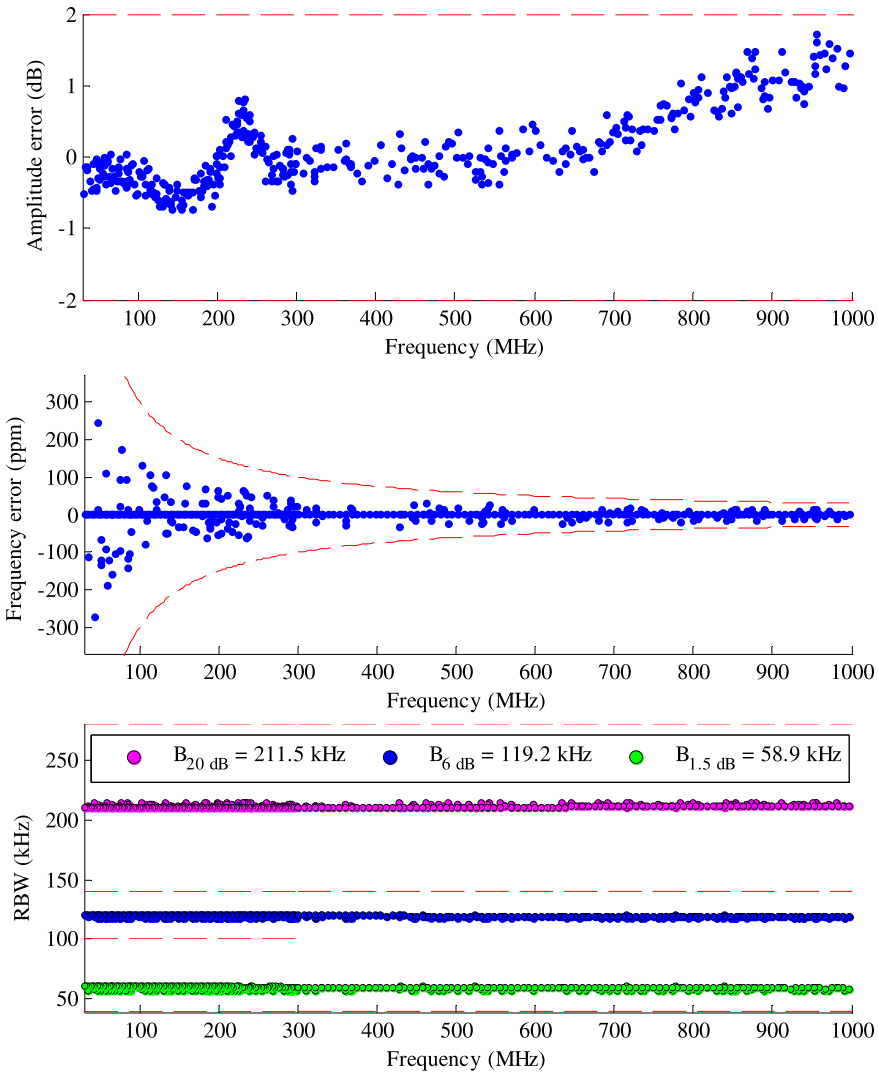

Fig. 12. Bands $\mathrm{C}$ and $\mathrm{D}$ sine-wave level error, frequency error, and selectivity assessment using pseudorandom multisine excitations for a full TDEMI measurement system.

each band. The amplitudes were uniformly distributed between 80 and $120 \mathrm{~dB}(\mu \mathrm{V})$, the phases were uniformly distributed in the $[0,2 \pi]$ range, and the frequencies where equidistantly chosen between the upper and the lower frequency of the band plus a random frequency shift uniformly distributed between $\pm \mathrm{RBW} / 2$.

In this regard, the three subplots in Fig. 12 show that the performance of the full TDEMI measurement system is compliant with standard requirements, since all the measured points are included in the tolerance margins declared in Table I. Interestingly, this methodology can be interpreted as an empirical Monte Carlo evaluation of the baseline parameters variability in measuring receivers.

Consequently, the statistical information obtained from previous measurements enabled additional exploitation of the result, comprising the analysis of the approximated distribution of the parameters under assessment.

Fig. 13 shows the histograms of relative frequency for the error in the amplitude of the measured tones. This information can be used in more realistic uncertainty estimations in EMI measurements.

\section{B. Absolute and Relative Pulse Response}

The pulse response assessment is shown in Fig. 14 for bands A and B (OSC 1) at the reference repetition frequency. The most relevant aspects to notice are the flatness of the frequency response and the ratios between peak/QP and QP 

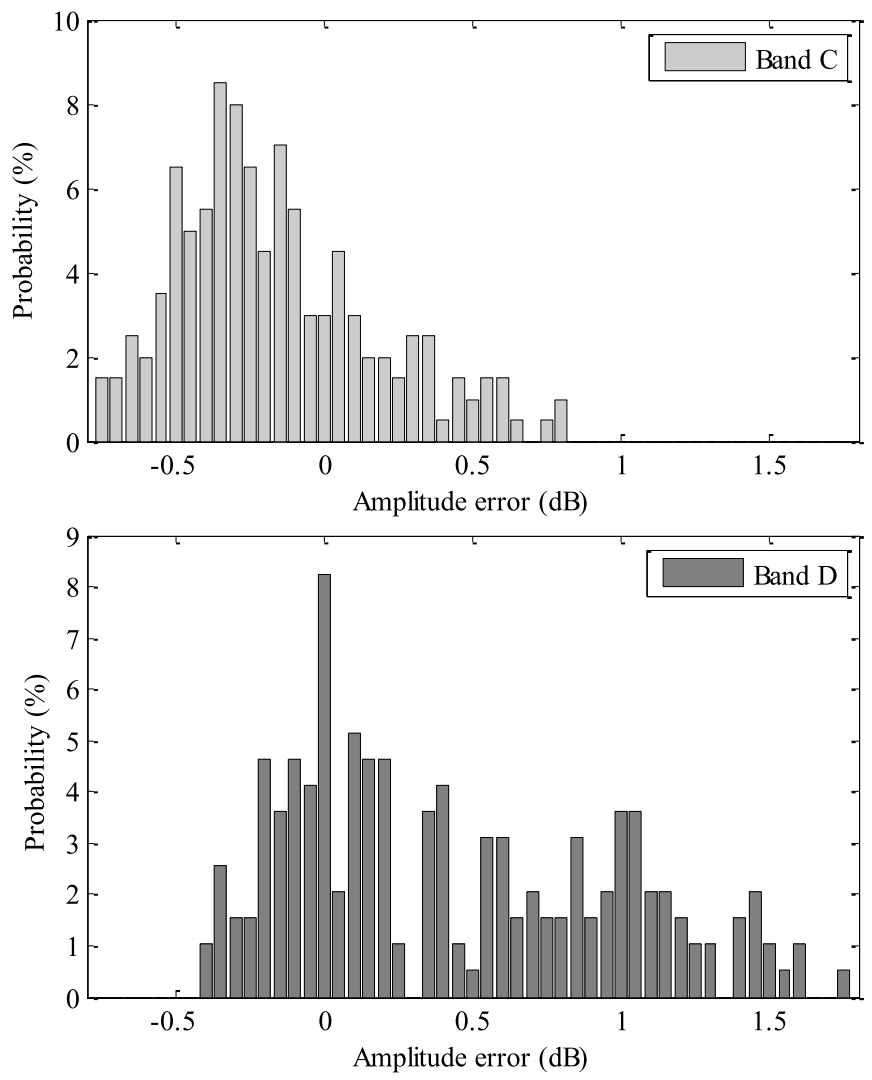

Fig. 13. Approximated empirical probability distribution for the amplitude error in sine-wave measurements for a measuring receiver in bands $\mathrm{C}$ and $\mathrm{D}$.
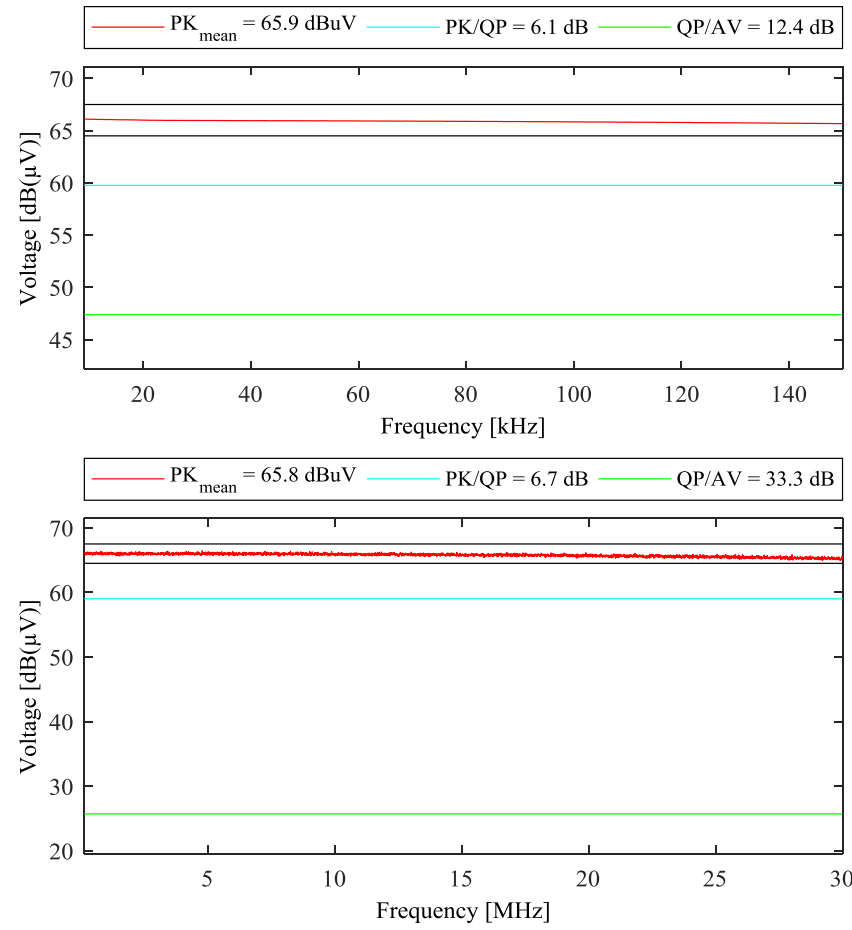

Fig. 14. Bands A (above) and B (below) assessment results of the absolute response to pulses for a full TDEMI measurement system (OSC1).

average, which fulfill standard requirements. It is important to highlight that this is a full-spectrum and multidetector characterization of the pulse response. For band A, the maximum errors registered were $0.7,0.17$, and $0.19 \mathrm{~dB}$ for the absolute
TABLE V

Results From the Relative Pulse Response Verification

\begin{tabular}{|c|c|c|c|c|c|c|}
\hline & Band & $\begin{array}{c}\boldsymbol{f}_{\text {rep }} \\
{[\mathrm{Hz}]}\end{array}$ & $\begin{array}{c}\mathbf{P K} / \mathbf{Q P} \\
{[\mathrm{dB}]}\end{array}$ & $\begin{array}{c}\mathbf{Q P} / \mathbf{Q P} \text { (ref) } \\
{[\mathrm{dB}]}\end{array}$ & $\begin{array}{c}\mathbf{A V} / \mathbf{Q P} \\
{[\mathrm{dB}]}\end{array}$ & $\begin{array}{c}\mathbf{R M S} / \mathbf{Q P} \\
{[\mathrm{dB}]}\end{array}$ \\
\hline \multirow{9}{*}{ రే } & A & 10 & 9.1 & 3.0 & & 7.6 \\
\hline & $\mathrm{A}$ & 25 (ref) & 6.1 & 0 & 12.4 & 4.5 \\
\hline & A & 60 & 3.1 & -2.9 & & \\
\hline & A & 100 & 2.1 & -4.0 & & -1.4 \\
\hline & B & 10 & 17.5 & 11.5 & & 25.1 \\
\hline & B & 20 & 13.2 & 6.6 & & \\
\hline & $\mathrm{B}$ & 100 (ref) & 6.7 & 0.0 & 33.1 & 14.9 \\
\hline & $\mathrm{B}$ & 500 & & & 23.2 & \\
\hline & $\mathrm{B}$ & 1000 & 2.1 & -4.5 & 17.8 & 4.8 \\
\hline \multirow{3}{*}{$\begin{array}{l}\tilde{U} \\
\text { రి }\end{array}$} & $C \& D$ & 100 (ref) & 11.9 & 0 & & 19.9 \\
\hline & $C \& D$ & 1000 & & -8.0 & 38.4 & 10.4 \\
\hline & $C \& D$ & 5000 & & & 26.4 & \\
\hline
\end{tabular}

$\mathrm{PK}$, the $\mathrm{QP} / \mathrm{PK}$, and the $\mathrm{QP} / \mathrm{AV}$ responses, respectively. For band $\mathrm{B}$, the maximum errors registered were $0.8,-0.13$, and $-0.4 \mathrm{~dB}$ for the absolute $\mathrm{PK}$, the $\mathrm{QP} / \mathrm{PK}$, and the $\mathrm{QP} / \mathrm{AV}$, respectively.

With regard the assessment of the relative pulse response, the results were satisfactory for both versions of full TDEMI measurement systems, that is, bands A and B for OSC1 and bands $\mathrm{C}$ and $\mathrm{D}$ for OSC2. Table $\mathrm{V}$ shows the mean value of the measurements performed in each frequency band. For bands $\mathrm{C}$ and $\mathrm{D}$, only pulse repetition frequencies above $100 \mathrm{~Hz}$ were validated due to the oscilloscope memory constraints that did not allow measuring sufficiently large time record. Additionally, for bands $\mathrm{C}$ and $\mathrm{D}$, pulse response measurements were performed at $30 \mathrm{MHz}, 300 \mathrm{MHz}$, and $1 \mathrm{GHz}$.

Table $\mathrm{V}$ results must be compared with Table II requirements in order to determine if the measured relative pulse response is within the tolerances defined in the CISPR 16-1-1 standard. For example, the specified relative response of the peak detector with respect to the QP detector at a repetition frequency of $20 \mathrm{~Hz}$ is $13.1 \pm 1.5 \mathrm{~dB}$ and the result from the assessment was $13.2 \mathrm{~dB}$, which is satisfactory. A similar analysis is applied to every band, detector and pulse repetition frequency.

\section{Measurement Uncertainty}

The accuracy of the measurement system is the foundation for a method to become accepted as relevant for the application it is intended to address. On the one hand, the waveform approach for assessing conformity of CISPR 16-1-1 measuring receivers would only be conclusive if the pulse generators provide excitation signals that are precise and well fitted to their expected mathematical representation (golden reference). On the other hand, it is also important to estimate the uncertainty of the measurements made with a full TDEMI measurement system following the CISPR 16-4-2 approach [24]. Therefore, this section discusses the appropriateness of the proposed assessment method in terms of the characterization of the pulse generators, the adequacy of the oscilloscopes' specifications (ADC dynamic figures) for 
EMI measurements, and the overall uncertainty analysis of the assessment performed to the full TDEMI measurement systems.

\section{A. Characterization of the Pulse Generators}

The 81160A pulse function arbitrary noise generator, which was used for obtaining most of the presented results, has 14 bits of vertical resolution in the DAC, can deliver up to $2.5 \mathrm{GSamples} / \mathrm{s}$, has a time resolution of $300 \mathrm{ps} \pm 50 \mathrm{ppm}$, and has a $330-\mathrm{MHz}$ bandwidth for pulses extendable to $500 \mathrm{MHz}$ for single tones. Similarly, the SML signal generators provide an accuracy in the sine-wave level that is better than $0.5 \mathrm{~dB}$ for frequencies below $2 \mathrm{GHz}$.

In practice, the spectrum of the abovementioned pulse generators can be calibrated using the black box approach focusing on the parameters that are relevant for assessing the EMI measuring receivers. Even if a comprehensive description of the calibration methods for pulse generators is beyond the scope of this paper, it is important to consider the following aspects.

First, the calibration of a CISPR pulse generator can be performed by several methods, such as the measurement of one spectrum line amplitude [25], the Fourier transform of time-domain pulse waveform [26], and the IF measurement method. From the metrology point of view, the most accurate is the Fourier transform from samples of a well-characterized oscilloscope (broadband sampling oscilloscope with characterized attenuators at the input). However, such a characterization is likely to be beyond the actual capabilities of secondarylevel calibration laboratories or in EMC test laboratories. Still, CISPR 16-1-1 Annex B states that "The impulse area should be known within $\pm 0.5 \mathrm{~dB}$ and the repetition frequency to within about 1\%" [1] can be shown to be achievable even by using low-grade oscilloscopes.

Conversely, calibrating the spectrum of complex multisinewave signals used in the assessment of the level accuracy is a more challenging task, because it is not possible to measure with a calibrated thermal or diode power detector. For this purpose, a calibrated spectrum analyzer could be used to tune the desired tone with proper RBW. Experience indicates that the typical uncertainty of this kind of measurement is below $0.2 \mathrm{~dB}$. Lower uncertainties could be achieved by using the FFT-method and metrology-level digitizers of appropriate resolution (16 bit or higher).

Finally, it is important to remark that metrological traceability is fundamental for the reliability of the proposed assessment method. The reference waveform generators must be characterized and calibrated independently before being used for assessing a measuring receiver. Moreover, any conformance testing report resulting from applying the proposed assessment method must include a statement of the uncertainty of the reference waveforms used for evaluating the measuring receiver.

\section{B. Oscilloscopes' Specifications and EMI Measurements}

Table VI presents the relevant specifications of OSC1 and OSC2 when they are configured at the actual operating settings
TABLE VI

Oscilloscopes Specifications at the Operating CONDitions CONFIGURED IN THE FULL TDEMI MEASUREMENT SYSTEM

\begin{tabular}{|c|c|c|c|c|}
\hline & & \multicolumn{3}{|c|}{ CISPR frequency band } \\
\hline & & A & $\mathrm{B}$ & $\mathrm{C} \& \mathrm{D}$ \\
\hline \multirow{6}{*}{$\underset{\mathscr{O}}{\check{O}}$} & Resolution (flexible) [bits] & 12 to 16 & 8 to 14 & - \\
\hline & ENOB [bits] & 8.1 to 8.7 & 7.9 to 8.2 & - \\
\hline & Enhanced resolution [bits] & 2 & 1.5 & - \\
\hline & Sampling frequency $[\mathrm{MS} / \mathrm{s}]$ & 62.5 & 125 & - \\
\hline & Time resolution $[\mathrm{ns}]$ & 16 & 8 & - \\
\hline & Bandwidth (Limited) [MHz] & 60 & 60 & - \\
\hline \multirow{6}{*}{$\underset{\mathscr{O}}{\tilde{O}}$} & Resolution (flexible) [bits] & - & - & 8 \\
\hline & ENOB [bits] & - & - & 6 \\
\hline & Enhanced resolution [bits] & - & - & 0.5 to 1.5 \\
\hline & Sampling frequency $[\mathrm{GS} / \mathrm{s}]$ & - & - & $1,2.5,5$ \\
\hline & Time resolution $[\mathrm{ns}]$ & - & - & $1,0.4,0.2$ \\
\hline & Bandwidth (Limited) [MHz] & - & - & $500 / 1000$ \\
\hline
\end{tabular}

of full TDEMI systems. In both cases, the specified accuracy of the signal level at the output of the generator is significantly better than the measurement accuracy of the oscilloscopes and satisfy the baseline requirements of CISPR 16-1-1 shown in Tables I and II. For those reasons, the suitability of the proposed assessment method is, in principle, granted for the application which it is intended.

Considering the criteria above, it is reasonable to assume that the errors observed in the sine-wave level characterization are primarily due to the receiver implementation under assessment. Henceforth, one could argue that even if the observed sine-wave level error is compliant with CISPR 16-1-1, the accuracy of the assessed full TDEMI measurement systems is rather low from a metrological perspective, in comparison to what could be expected entirely from frequency-domain receivers.

Nonetheless, it is important to remind that in practice, when it comes to real-life EMI measurements, the most important feature of a test receiver is its capability for detecting noncompliant electromagnetic emissions and worst case disturbance events. That is the key reason why FFT-based systems offer advantages to practitioners, even if this means compromising the dynamic range, the sensitivity, and the accuracy in comparison to measuring receivers based on the superheterodyne architecture. In fact, this is possible thanks to the not-sorestrictive baseline requirements of CISPR 16-1-1.

\section{Uncertainty on the Assessment of Full TDEMI Receivers}

The main contributions to the uncertainty in the measurement performed during the assessment are associated with the signal acquisition (cable attenuation, mismatch, ADC resolution, thermal noise, linearity, and so on) and to the signal processing.

In that sense, the uncertainty contribution due to impedance mismatch, $u_{M}$, between the cable from the signal generator and the oscilloscope channel is given by

$$
u_{M}=\frac{1}{\sqrt{2}} 20 \log \left(1+\left|\Gamma_{1}\right|\left|\Gamma_{2}\right|\right)
$$


TABLE VII

General UnCERTAinty Budget for the Assessment of a FulL TDEMI MEASURING RECEIVER

\begin{tabular}{lccc}
\hline Quantity & Estimate & Standard uncert. & $\begin{array}{c}\text { Prob. } \\
\text { Distrib. }\end{array}$ \\
\hline $\begin{array}{l}\text { Cable transfer } \\
\text { function }\end{array}$ & $0.1 \mathrm{~dB}$ & $0.05 \mathrm{~dB}$ & Rectangular \\
\hline $\begin{array}{l}\text { Impedance } \\
\text { mismatch }\end{array}$ & $0.1 \mathrm{~dB}$ & $0.07 \mathrm{~dB}$ & U-shaped \\
\hline $\begin{array}{l}\text { Oscilloscope } \\
\text { freq. response }\end{array}$ & $\pm 0.2 \mathrm{~dB}$ & $0.1 \mathrm{~dB}$ & Rectangular \\
\hline $\begin{array}{l}\text { Oscilloscope } \\
\text { DC accuracy }\end{array}$ & $0.1 \mathrm{~dB}$ & $0.05 \mathrm{~dB}$ & Rectangular \\
\hline $\begin{array}{l}\text { Oscilloscope } \\
\text { linearity error }\end{array}$ & $0.1 \mathrm{~dB}$ & $0.05 \mathrm{~dB}$ & Rectangular \\
\hline $\begin{array}{l}\text { Oscilloscope } \\
\text { timebase }\end{array}$ & $0 \mathrm{~dB}$ & $0.06 \mathrm{~dB}$ & Normal \\
\hline $\begin{array}{l}\text { Osc. Vert. } \\
\text { resolution }\end{array}$ & $0 \mathrm{~dB}$ & $0.02 \mathrm{~dB}$ & Triangular \\
\hline $\begin{array}{l}\text { Sig. generator } \\
\text { error }\end{array}$ & $0 \mathrm{~dB}$ & $0.2 \mathrm{~dB}$ & Regtangular \\
\hline $\begin{array}{l}\text { Processing } \\
\text { error }\end{array}$ & $0 \mathrm{~dB}$ & $0.05 \mathrm{~dB}$ & Normal \\
\hline $\begin{array}{l}\text { Repetitivity } \\
\text { (Type A) }\end{array}$ & $0.1 \mathrm{~dB}$ & $0.05 \mathrm{~dB}$ & Normal \\
\hline $\begin{array}{l}\text { Combined uncertainty }\left(u_{c}\right) \\
\text { Expanded uncertainty }\left(2 u_{c}\right)\end{array}$ & $0.27 \mathrm{~dB}$ & $\mathbf{0 . 5 4} \mathrm{dB}$ & \\
\hline
\end{tabular}

where $\Gamma_{1}$ is the reflection coefficient of the cable and $\Gamma_{2}$ is the reflection coefficient of the oscilloscope.

Moreover, the uncertainty of the limited oscilloscope vertical resolution, $u_{\text {res }}$, is given by

$$
u_{\text {res }}=\frac{2}{\sqrt{6}} \frac{U_{\text {max }}}{U_{\text {meas }}\left(2^{\mathrm{ENOB}}\right)} * 100[\%]
$$

where $U_{\max }$ is the full vertical scale, $U_{\text {meas }}$ is the measured amplitude, and $1 / \sqrt{ } 6$ is due to the triangular distribution. Moreover, there is also the uncertainty contribution of the oscilloscope gain at dc, which is calibrated with a precision dc source and digital voltmeter.

Likewise, the uncertainty due to the oscilloscope noise can be calculated using

$$
u_{\text {noise }}=\sqrt{4 k T B R}
$$

were $k$ is the Boltzmann constant, $T$ is the temperature in Kelvin, $B$ is the oscilloscope bandwidth, and $R$ is the oscilloscope input impedance.

Finally, the uncertainty contribution of the oscilloscope's linearity and time base errors is evaluated using precise and well-known sinusoidal test signals of different amplitudes and frequencies.

Regarding the uncertainty contribution of the signal processing performed by the full TDEMI software, $u_{\mathrm{DSP}}$, it is due to the mathematical operations of windowing, resampling, flatness correction, padding, and rounding, among others, that are performed before providing the EMI measurement results to the end user. This uncertainty contribution has been bounded to less than $0.05 \mathrm{~dB}$ in $99 \%$ of cases. This estimation has been made by means of testing the algorithms with ideal mathematical representations of the input signal. Monte Carlo simulations have been used to exercise the algorithms with millions of possible combinations of the actual measurement parameters in order to obtain a realistic quantification.

Table VII shows an example of the measurement uncertainty estimated for the assessment of the full TDEMI measurement system based on OSC1 for CISPR band B. This general budget can be filled with the values of other bands or oscilloscope models.

\section{CONCLUSION}

In this paper, a time-domain-based waveform approach was used for assessing the conformity of measuring receivers with respect to CISPR 16-1-1 requirements. The frequency range covered was $9 \mathrm{kHz}-1 \mathrm{GHz}$, comprising CISPR bands A-D. The proposed test setups are more affordable, versatile, and flexible than conventional implementations based on manufacturer's calibration methods. Moreover, it was demonstrated that the usage of the CISPR baseband pulse generator can be avoided by taking alternative approaches such as employing AWG. In fact, results could encourage test houses and manufacturer-independent industrial calibration laboratories to implement their own assessment bench for the internal verification of the receiver's baseline requirements. A key advantage of this approach is that waveforms can be represented as numerical vectors and they could be easily reproduced or shared by any laboratory having an adequate AWG. On the other hand, the scalability of our approach is granted with the usage of AWG of broader capacity.

\section{REFERENCES}

[1] Specification for Radio Disturbance and Immunity Measuring Apparatus and Methods-Part 1-1: Radio Disturbance and Immunity Measuring Apparatus-Measuring Apparatus, IEC Standard CISPR 16-1-1 ed4.0, 2015.

[2] R. D. Drosd, "Transmission line pulse generator," U.S. Patent 2769 101, Jul. 29, 1955.

[3] A Guide to Calibrating Your Spectrum Analyzer, Fluke Corp., Everett, WA, USA, 2006.

[4] C. Rauscher, Fundamentals of Spectrum Analysis, 5th ed. Munich, Germany: Rohde \& Schwarz, 2011.

[5] (2015). Publishable Summary for 15RPT01 Microwave Development of RF and Microwave Metrology Capability. Accessed: Oct. 9, 2017. [Online]. Available: http://rfmw.cmi.cz/documents/misc/15RPT01 _Publishable_Summary.pdf

[6] R. B. Andrews, "An impulse spectral intensity measurement system," IEEE Trans. Instrum. Meas., vol. 15, no. 4, pp. 299-303, Dec. 1966.

[7] M. Zeier. (Aug. 3, 2009). EURAMET Project 1064: Spectrum of Pulse Generators in Accordance With CISPR-16-1-1, BernWabern, Switzerland, Accessed: Oct. 9, 2017. [Online]. Available: https://www.euramet.org/get/?tx_stag_base\%5Bfile $\% 5 \mathrm{D}=3404 \&$ tx_stag _base $\% 5$ Baction $\% 5 \mathrm{D}=$ downloadRaw\&tx_stag_base $\% 5 \mathrm{~B}$ controller\%5D $=$ Base

[8] M. A. Azpúrua, M. Pous, F. Silva, and J. A. Oliva, "Fast and automated verification of multi-channel full time-domain EMI measurement systems," in Proc. IEEE Int. Instrum. Meas. Technol. Conf. (I2MTC), Turin, Italy, May 2017, pp. 785-790.

[9] P. Russer, "EMC measurements in the time-domain," in Proc. 30th URSI Gen. Assembly Sci. Symp., Istanbul, Turkey, Aug. 2011, pp. $1-35$.

[10] V. Iglesias, J. Grajal, M. A. Sánchez, and M. López-Vallejo, "Implementation of a real-time spectrum analyzer on FPGA platforms," IEEE Trans. Instrum. Meas., vol. 64, no. 2, pp. 338-355, Feb. 2015.

[11] D. Liebl, Measuring With Modern Spectrum Analyzers. Munich, Germany: Rohde \& Schwarz, Mar. 2013. 
[12] M. A. Azpúrua, M. Pous, and F. Silva, "A measurement system for radiated transient electromagnetic interference based on general purpose instruments," in Proc. IEEE Int. Symp. Electromagn. Compat. (EMC), Dresden, Germany, Aug. 2015, pp. 1189-1194.

[13] M. A. Azpúrua, M. Pous, S. Çakir, M. Çetintaş, and F. Silva, "Improving time-domain EMI measurements through digital signal processing," IEEE Electrmagn. Compat. Mag., vol. 4, no. 2, pp. 82-91, 2nd Quart., 2015.

[14] R. Lapuh, B. Pinter, B. Voljc, Z. Svetik, and M. Lindic, "Digital oscilloscope calibration using asynchronously sampled signal estimation," IEEE Trans. Instrum. Meas., vol. 60, no. 7, pp. 2570-2577, Jul. 2011.

[15] M. Monti, E. Puri, and M. Monti, "Hidden aspects in CISPR 16-1-1 full compliant fast Fourier transform EMI receivers," in Proc. Int. Symp. Electromagn. Compat. (EMC EUROPE), Wroclaw, Poland, Sep. 2016, pp. $34-39$.

[16] A. Mariscotti, "On time- and frequency-domain equivalence for compliant EMI measurements," in Proc. IEEE Instrum. Meas. Technol. Conf. (IMTC), Warsaw, Poland, May 2007, pp. 1-5.

[17] S. Braun, T. Donauer, and P. Russer, "A real-time time-domain EMI measurement system for full-compliance measurements according to CISPR 16-1-1," IEEE Trans. Electromagn. Compat., vol. 50, no. 2, pp. 259-267, May 2008.

[18] H. H. Slim, C. Hoffmann, S. Braun, and P. Russer, "A novel multichannel amplitude probability distribution for a time-domain EMI measurement system according to CISPR 16-1-1," in Proc. 10th Int. Symp. Electromagn. Compat., York, U.K., Sep. 2011, pp. 22-25.

[19] J. Medler, "Use of FFT-based measuring instruments for EMI compliance measurements," in Proc. Int. Symp. Electromagn. Compat., Tokyo, Japan, May 2014, pp. 89-92.

[20] M. Friese, "Multitone signals with low crest factor," IEEE Trans. Commun., vol. 45, no. 10, pp. 1338-1344, Oct. 1997.

[21] C. Keller and K. Feser, "Fast emission measurement in time domain," IEEE Trans. Electromagn. Compat., vol. 49, no. 4, pp. 816-824, Nov. 2007.

[22] Limits and Methods of Measurement of Radio Disturbance Characteristics of Electrical Lighting and Similar Equipment, IEC Standard CISPR 15 ed8.1, 2015.

[23] Electromagnetic Compatibility of Multimedia Equipment-Emission Requirements, IEC Standard CISPR 32 ed2.0, 2015.

[24] Specification for Radio Disturbance and Immunity Measuring Apparatus and Methods-Part 4-2: Uncertainties, Statistics and Limit ModellingMeasurement Instrumentation Uncertainty, IEC Standard CISPR 16-4-2 ed2.1, 2014

[25] P. G. A. Jespers and G. A. Jackson, "Calibration of nanosecond pulse generators," IEEE Trans. Electromagn. Compat., vol. EMC-14, no. 2, pp. 68-72, May 1972.

[26] S. Pasakawee and V. Sittakul, "Calibration and uncertainty evaluation of pulse generator for EMC testing using FFT technique," in Proc. 13th Int. Conf. Elect. Eng./Electron., Comput., Telecommun. Inf. Technol. (ECTI-CON), Chiang Mai, Thailand, Jun./Jul. 2016, pp. 1-5.

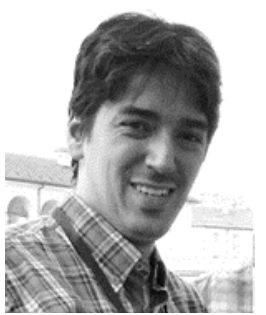

Marco A. Azpúrua (S'07-M'13) received the B.Sc. degree in telecommunications engineering and the M.Sc. degree in electrical engineering from the Universidad Central de Venezuela, Caracas, Venezuela, in 2008 and 2013, respectively. He is currently pursuing the Ph.D. degree with the Electromagnetic Compatibility Group, Universitat Politècnica de Catalunya, Barcelona, Spain.

He was a Researcher with the Applied Electromagnetics Laboratory, Foundation Engineering Institute, Caracas. His current research interests include electromagnetic compatibility, antenna and microwave measurement technologies, and the estimation of measurement uncertainty in complex systems and validation methods.

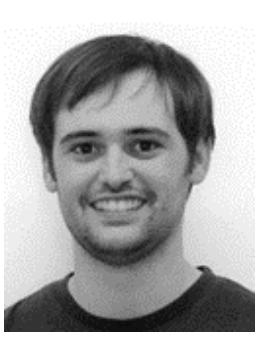

Marc Pous was born in Barcelona, Spain, in 1983. He received the M.Sc. degree in telecommunications engineering and the Ph.D. degree in radiated transient interferences and digital communication systems evaluation from the Universitat Politècnica de Catalunya, Barcelona, in 2009 and 2015, respectively.

From 2003 to 2006, he was with the Department of Electromagnetic Compatibility, LGAI Technological Centre S.A., Barcelona. Since 2006, he has been with the Electromagnetic Compatibility Group, Universitat Politècnica de Catalunya, where he has been participating in international and national research projects related with automotive, aerospace, railway, and medical industries. His current research interests include the development of time-domain measurement techniques to capture interferences, which are not properly measured following the harmonized electromagnetic compatibility standards.

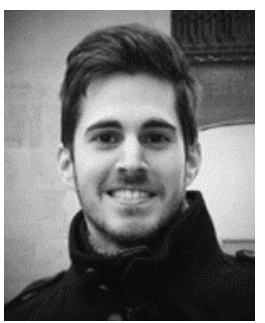

José A. Oliva was born in Barcelona, Spain, in 1991. He received the M.Sc. degree in telecommunications engineering from the Universitat Politècnica de Catalunya (UPC), Barcelona, in 2016.

Since 2016, he has been with the Electromagnetic Compatibility Group, UPC, where he has been involved in the development of a measuring system in the time domain for the electromagnetic interference. His current research interests include electromagnetic compatibility.

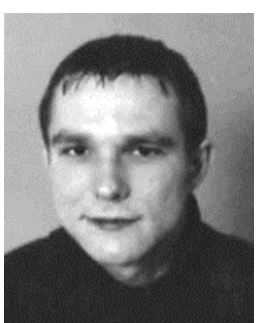

Borut Pinter was born in Murska Sobota, Slovenia, in 1975. He received the B.Sc. degree in physics from the Faculty for Mathematics and Physics, University of Ljubljana, Ljubljana, Slovenia, in 2005.

$\mathrm{He}$ joined the Slovenian Institute of Quality and Metrology, Ljubljana, in 2003, where he is currently a Research and Development Scientist. He is currently involved in local and international research projects. His current research interests include the field of high frequency (RF and microwave) electrical metrology, time and frequency, acoustics and vibration, dc and low-frequency impedance (capacitance, resistance, and inductance), and optical fiber metrology.

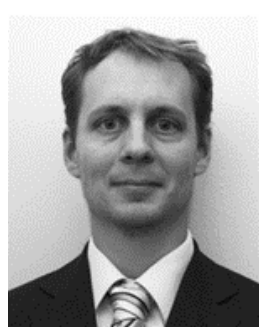

Martin Hudlička (S'04-M'08-SM'15) received the M.Sc. degree in engineering and the Ph.D. degree in electrical engineering from Czech Technical University in Prague, Prague, Czech Republic, in 2004 and 2007, respectively. His Ph.D. thesis was related to the propagation of electromagnetic waves in periodic structures.

He joined the Department of Primary Metrology of RF Electrical Quantities, Czech Metrology Institute, Prague, in 2007, where he is currently a Metrologist and a Researcher. His current research interests include microwave and millimeter-wave measurements and modern communication technologies.

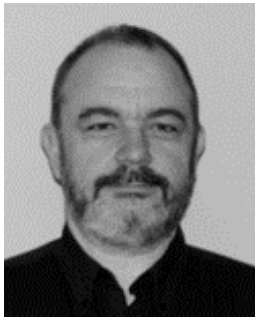

Ferran Silva (M'76-SM'81-F'87) received the M.Sc. and Ph.D. degrees from the Universitat Politècnica de Catalunya (UPC), Barcelona, Spain, in 1989 and 1997, respectively.

Since 2000, he has been the Director of the Electromagnetic Compatibility Group, UPC, performing technology transfer activities to the industrial sector, where he is currently an Associate Professor of electronics with the Department of Electronic Engineering. He has published over 90 papers in journals and conferences, and contributed to the Wiley Encyclopedia of Biomedical Engineering. He has participated in 14 research projects related to electromagnetic compatibility (EMC). His current research interests include EMC in near field and time domain, including transients, with application to automotive, medical systems, and installations.

Dr. Silva is a member of the IEEE EMC Society and the Spanish Standardization Committees SCTC77-210 and the CTN208 SCCISPR210A. He is the Head of the Spanish Chapter of the IEEE. He was the Chairman of the EMC Europe 2006 International Symposium. Since2006, he belongs to the Board of Chairman of EMC Europe. 